\title{
Lost in Transition: An Analysis of Post-colonial Dilemma and National Identity in Three Contemporary Novels from East and Southeast Asia
}

\author{
Thanis Bunsom \\ Department of Language Studies, School of Liberal Arts \\ King Mongkut's Universitty of Technology Thonburi, Bangkok, Thailand \\ Email: thanis.bun@kmutt.ac.th
}

\section{Doi:10.5901/mjss.2014.v5n15p615}

\begin{abstract}
After several centuries of being colonised by European powers, East and Southeast Asian countries were struggling to come to terms with their post-colonial national identities. Post-independent dilemmas were rooted in the core issues of cultural fragmentation and individualistic alienation in which formerly-colonised citizens felt at loss spiritually within their newlydemarcated political borders. Not knowing which cultural direction their countries were going to take, people faced the quandary of straddling the opposite world of East and West. This alarming issue has become a focal point in a lot of contemporary literature from East and Southeast Asia, reflecting the people and countries' ongoing quests to find their places in the modern global society. This paper analyses such dilemmas and their unremitting search of identity through three contemporary novels from Macau, Indonesia and Singapore. The Bewitching Braid (Macau) by Henrique de Senna Fernandes explores the unknown fate of independence faced by the Chinese, Macanese and Portuguese alike. Abdoel Moeis's Never the Twain (Indonesia) is an allegory for Indonesia in a political transition and a struggle towards a national identity. Mammon Inc. by Hwee Hwee Tan deals vigorously with the Singaporean society, torn between the Taoist values of the Eastern world and the technological advance of its Western counterpart.
\end{abstract}

Keywords: Post-colonial dilemma, National Identity, The Bewitching Braid, Never the Twain, Mammon Inc.

\section{Introduction}

The concept of nationalism and national identity emerged in the late eighteenth century Europe (Smith, 1991) when awareness of nation building began and has since become a subject of wide academic discussion because of its problematic complexities. As several academics have observed, explanations on the definitions of nationalism and national identity should not and cannot be simply kept within the specification of cultural and political factors that contribute to the building and growth of a nation (Özkirimli, 2000). The real challenge lies in an interrogation as to how the notion of nationalism has instilled such deep attachments and created feelings of patriotism and mutuality. As Anderson (1983), phrases it, the crucial question is: [w]hat makes the shrunken imaginings of recent history generate such colossal sacrifices?" (7). Interestingly, according to his view, nations are merely imaginings and therefore, people in each nation co-exist in what he terms 'imagined communities' where despite not knowing, hearing or meeting their fellow members, "in the minds of each lives the image of their communion" (6). With the similar image of a nation in mind, a national identity can be formed and upheld by people in the nation. This groundbreaking proposal is supported by his idea of printed languages and publications as bases for national consciousness. Newspapers, propagandas and books, for example, are factors underlying the rise of nations and the inventions of nationalism and national identities.

Those social phenomena, as Anderson argues, are also believed to be a result of the "modular" development of nationalism that started in Latin America and Europe before arriving into Africa and Asia (50). It seems, therefore, that processes of nation building, nationalism and national identities are not restricted in one particular part of the world but instead, contagious in a sense that most countries, if not all, have partaken on experiences of European colonisation, either directly or indirectly. Said (1978) and other prolific post-colonial scholars such as Fanon (1961) and Spivak (1988) posit that the modern world is dictated by the 'Eurocentric universalism' in which superiority is interrelated with the Europeans, or white-skinned people to be exact, whereas inferiority is perpetually assigned to the 'Other', or the nonEuropeans. This point of departure reveals the troubled reality in which complications of constructing a national identity after independence based on the European colonisers' cultural and political interferences are to be expected. The issue is further clarified by Chatterjee (1996) that "[h]istory has decreed that we in the postcolonial world shall only be perpetual consumers of modernity...Even our imaginations must remain forever colonized" (216). 
In East and Southeast Asia, the experiences of being colonised by the European powers are not unusual. Parts of China, including Hong Kong and Macau, were colonised by the British Empire, France and Portugal; one half of Southeast Asia belonged to the British Empire whereas the other half belonged to France, with the exceptions of Indonesia, the Philippines and East Timor that were under the sovereignty of the Netherlands, Spain and Portugal respectively. As each nation or territory in East and Southeast Asia began to claim their autonomous rights to govern themselves in the second half of the twentieth century, more and more pressuring questions were raised to the newlyemerging nation states as to what directions they were going to take and how they were going to define themselves politically, socially and culturally in the post-independent era (Kahn, 1998). Those questions certainly problematised the political and cultural self-representations of the East and Southeast Asian former colonies, inevitably compelled to take into consideration the three relevant criteria: existing indigenous cultures, imposed European traditions and emerging hybridity or cultural polyvalency.

Literature, as its functions would serve, does not fail to capture the sentiments of people in the midst of historical transitions that would determine the future of their countries. Post-colonial literature from the regions has aptly demonstrated the countries and the people's frustration of not being able to find their own identity due to the strong influences of the colonial powers. A number of writers, from the 1920s onwards, for instance, create stories to discuss, debate and express their sense of insecurity and confusion over their national and cultural identities contaminated by Western characteristics. The analysis of literature can therefore shed light into the historical events and the psychological states of the colonised subjects.

\section{Literature Review}

Due to the large number of publications related to the issues in question, in this section, two areas of relevant academic research are briefly reviewed in order to exhibit their perplexing nature: national identity and post-colonial literature.

\subsection{National Identity}

The idea or definition revolving around national identity demonstrates great difficulties that scholars have encountered. Several western scholars recognise the challenge in attempting to give proper definitions to the term 'national identity'. Smith (1991) proposes that the concept of national identity relies heavily on "the resurgence of the tide of nationalism" and hence it is a "collective phenomenon" with "a multidimensional concept" (vii). To reinforce the collectivity, the state must perpetually exploit symbols, ceremonies and customs. However, as the word 'identity' itself, either individual or collective, is troublesome enough, as Smith argues, the imposition of a collective national identity in a nation of multiethnic groups has the potential for the proliferation of conflicts. In another work of his, Smith (1992) discusses the future of European unity in which the established Pan-European culture and identity could potentially be "antithetical to the development of a cosmopolitan culture" in post-industry society (1). His caution has proven true in many aspects, considering later scholarly studies such as Kumar (2003) and Huntington (2004) that deal extensively with the identity crises of Great Britain and the US respectively. In Kumar's studies, he pinpoints the difficulty of distinguishing the English from the British identity. While Great Britain comprises four autonomous territories, England's hegemony seems to take over the rest of the British Isles. Huntington, on the other hand, puts the question of American identity in the forefront and recognises the ongoing struggles between the preeminent, salient culture, symbolised through the US flag, on one side and subnational, dual-national and transnational cultures on the other.

The struggle to claim a national identity is not a phenomenon exclusive only to the West. In Asia, numerous conflicts arise as a result of national identity quests. Penetrated by the political and cultural ideologies of the European colonisers, East and Southeast Asian countries and territories have been faced with identity dilemmas. Huat (1998) deploys his homeland, Singapore as a foreground for a competition of identities. Consisting of Chinese, Malay, Indian and Eurasian, Singapore is definitely multiethnic and multiracial. Despite the idea of Asian Values proposed by the government, the country cannot rid itself from the western cultural influences. Like Singapore, two Asian city states, Hong Kong and Macau, encounter the same problem. As Brookshaw (2002) describes, the challenges caused by the territories' transitions after 1997 and 1999 stir a sense of unpredictability of the future. Becoming more of international centres intended by the newly-appointed leaders backed by Beijing, Hong Kong and Macau's unique characteristics of east-meetwest could regrettably fade. 


\subsection{Post-colonial Literature}

According to Hall (2005), post-colonial literature or foreign literature produced in European languages such as English, French or Portuguese, derived from the colonial times when European literature was made available in the education system of the colonies. In the English context, India was one of the first British colonies exposed to the writings of great literary authors. Nevertheless, as Pennycook (1998) argues, in absorbing the literature produced by English writers, the colonised subjects were forced to absorb the English identity against the Others in the East.

This historical centrality of European identity in literature has led to the production of literary works from the perspectives of the Others. Through literature, writers seek to express their own voices, tell their stories and show the world their experiences of pain and suffering. Since the twentieth century, a number of authors from Africa and Asia have published their works in European languages that they have acquired from the colonial times. Nigeria and South Africa, the countries whose literature in English supersedes that of other African countries, are clear examples of how the English language has influenced the realm of national cultures (Dathorne, 1975). Prominent writers such as Chinua Achebe, Chimamanda Ngozi Adichie, Nadine Gordimer and J.M.Coetzee are widely known and studied in education institutes across the world. In Asia, Indian, Hong Kong Chinese, Malaysian and Singaporean writers play a very significant role in the post-colonial literary world, ranging from Salman Rushdie, Aravind Adiga, Xu Xi, Nury Vittachi, Tash Aw to Catherine Lim, Philip Jerayetnam and Hwee Hwee Tan. The lists, in actuality, are countless. As for other European languages, literature in Portuguese and French can also be found in Goa (India), Macau, East Timor and Indochina. The number of works, however, is not as abundant as those in English.

In academe, a number of research and studies by scholars have been done on Indian and African literature (see Chabal et al., 1996; Gover et al., 1999; Gopal, 2009; Spillman, 2009; Boehmer \& Chaudhuri, 2010; Helff, 2013; Varughese, 2013; Krishnan, 2014 as examples among others); nonetheless, not as many have been on East and Southeast Asian literature in European languages as they have only recently attracted scholars in the field. Most of the works give an overview of writings from the regions; only a few offer in-depth analyses of individual works or writers. Examples of academic work on post-colonial East and Southeast Asian literature include Brookshaw (2002) on Portuguese literature from Macau, Singh (Ed.) (1998) on Singaporean literature, Thumboo (Ed.) (2007) on Asia-Pacific literature in Englishes, Patke \& Holden (2010) on Southeast Asian writing in English, Nguyen (2003) on Vietnamese Francophone novels and Xu Xi \& Ingham (2003) on literature in English from Hong Kong.

\section{Research Question}

Because of the limited number of literary analysis of individual writings from the two regions, this research aims at filling the gap and answering the much-debated question of national identity:

How is the concern over post-independent national identity depicted in literary works from East and Southeast Asia?

\section{Research Methodology}

\subsection{Data}

As aforementioned, as a result of European imperialism and the colonised subjects' acquisition of European languages, a large number post-colonial literary works have emerged since the beginning of the twentieth century. For this study, three canonical novels, among hundreds, were selected to be representatives of the post-colonial writings from East and Southeast Asia. They were Abdoel Moeis's Never the Twain (1928) from Indonesia, Henrique de Senna Fernandes's The Bewitching Braid (1993) from Macau and Hwee Hwee Tan's Mammon Inc. (2001) from Singapore. The selection was made based on the following criteria. First, the three works were written by widely-accepted writers whose literary creations are regarded as the benchmark of their national literature. While Moeis is respected by his people and his works studied in Indonesian schools, Fernandes, a Eurasian writer, predicts the future of his homeland and the Macanese people in several of his works, viewed as the original voice of Macau literature (Brookshaw, 2002). Tan, a Singaporean writer in her thirties, is one of the few Southeast Asian writers whose works were published in the West. Two of her novels, Foreign Bodies (1997) and Mammon Inc. (2001), were published by Penguins and received numerous awards. The other criterion for the inclusion of the three works was the subject matter. As three novels in the study deal with the issue of national identity, they can serve the purpose of the research's objectives. 


\title{
4.2 Research Procedures
}

The research was conducted based on the following procedures. First, the research question was posed and the novels were selected. After the selection, relevant literature, namely national identity and postcolonial theories, was reviewed. Then, the three novels were analysed based on the existing literature to answer the research question. The method of analysis was the content analysis. Finally, the research paper was written up, revised and edited.

\subsection{Limitations of the Study}

As far as the concept of national identity is concerned, no piece of academic research could be completed without generating further complications or questions. In this study, I attempted to deploy three novels to demonstrate the struggle and dilemma of countries and people in their search of national identity. The conclusion given in this paper could merely represent partial ideas and concerns of the writers, not of the majority of the people. Also, as the analysis relies on my interpretation, it could yield controversy and disagreement among literary academics and enthusiasts. Nevertheless, as the discipline of literature is concerned, room for interpretation should be welcome, not rejected. The perspectives offered in this research should thus yield clarifications to the existing readings.

\section{Results and Discussion}

The analysis of the three novels clearly demonstrates dilemmas experienced by the characters in the stories in the pursuit of national identity after independence. More details are explicated as follows:

\subsection{Never the Twain}

The novel's original title in Indonesian, Salah Asuhan, immediately takes the reader to the heart of the problem. Salah asuhan literally means a wrong upbringing, referring to Indonesia's wrong colonial policy implemented by the Dutch colonisers to repress the local population. Written in the 1920s, the novel depicts a typical picture of hierarchical colonial societies, with the White population on the top of the pyramid, succeeded by the Eurasians, the local, Dutch-educated elite and the local people. The complicated relationship among the three main characters, Hanafi, Corrie and Rapiah serves as the central conflict of the novel and simultaneously as the allegory for the palpability of anxiety over the future of Indonesia.

To elaborate, Hanafi, the main protagonist, is madly in love with Corrie, a beautiful, free-spirited Eurasian woman but engaged to Rapiah, a native, submissive woman. In this triangle love, Hanafi represents troubled Indonesia at the intersection of colonisation and independence. Corrie, on the other hand, stands for the powerful European legacy that would continue to dominate the archipelago after independence. Interestingly, she is portrayed by Moeis as being independent, seductive and tempting, the qualities that are irresistible to Hanafi. Rapiah, the other female character, possess quite the opposite characteristics; she is sweet, gentle and docile, the qualities that Asian readers are familiar to and can identify with. Torn between his desire to pursue Corrie and her European culture, Hanafi cannot however sever the ties with Rapiah, representing the local Indonesian culture, that he is obliged to carry on. Allegorically speaking, Hanafi's dilemma epitomises the cloudy future of post-independent nation in its attempt to define national identity as described in the following passage:

\begin{abstract}
"Rapiah and Corrie, he realized, were equally noble, each with her own beauty. One was a flower from the East, the other from the West. At first, he thought he was at one with the West, and would find happiness with Corrie. But he now realized that there was a part of him that was so Eastern, that it could not be erased by any education. So deeply was it planted in his soul, and so thoroughly absorbed into his blood, that it was as though he had drunk his essence of Easternness in his mother's milk." (203)
\end{abstract}

The passage evidently describes Hanafi's as well as Indonesia's sense of indecisiveness. Colonised by the Dutch for centuries, the nation-to-be could not decide which cultural directions, which serve as a underlying factor for its national identity construction, it was supposed to take. While the European ways of life, accustomed by few of the educated elite population such as Hanafi, may pave ways for the future of the independent nation in the international sphere, the local culture, filled with exoticism, beauty and originality buries deep within the nation's soul. Choosing one over the other seems to be impossible. The ending of the book is as ambiguous as the notion of national identity itself because in 
eventuality, Hanafi's marriages to both girls are a failure and he chooses to take his own life. In his death, complications arise as considerable controversy revolves around the question of where he should be buried: "a village cemetery as a native or in the government one as a European" (Hoadley, 1996, p. 123). Moeis's allegory regarding the despondency of Indonesia is obviously loud and clear.

\subsection{The Bewitching Braid}

In its original Portuguese title, A Trança Feiticeira gives its reader a sense of exotic clandestine. That is, stereotypically speaking, braids are usually related to Eastern women and the bewitching nature, from the Western perspectives, recollects fatal seductiveness. The mysterious nature of the title can well explain the unique characteristics of a former Portuguese colony in the Far East, Macau. Taken over by the Portuguese in the sixteenth century, the tiny island became divided by two groups of its residents: the Portuguese in the centre and the Chinese in the periphery. Intermediaries between the two groups were the Macanese, half-European, half-Chinese born on the island. The debate on Macanese identity is of interest to several scholars (see Pina-Cabral, 2002; Wei (Ed.), 2014; Wong \& Wei (Eds.), 2014 among others) and is included in a number of literary works.

The approach of $31^{\text {st }}$ December 1999 brought with it a lot of anxiety over the future of Macau. Although the 'one country, two systems' was promised by the Beijing government, people's confusion and fear remained indomitable. Fernandes offered his reader an idealistic ultimatum: a social and cultural negotiation between Portugal and China. The Bewitching Braid, written in 1993, can therefore be regarded as a "politically correct" novel, approved by both Macau government and Chinese government (Brookshaw, 2002). Two protagonists, Adozindo, a Macanese man and A-Leng, a Chinese woman, are in love despite strong objections from both of their families. Excluded from their societies, the couple lives their married life based on the understanding and negotiations of their cultural differences Adozindo speaks Cantonese, the dominant language spoken by the locals, works for a Chinese employer and celebrates Chinese religious ceremonies. A-Leng, on the other hand, adopts Christianity, wears Western dresses whenever required, and raises their children to speak both Cantonese and Portuguese, have faith in Christianity and still maintain a sense of filial piety, a very important characteristic of the Chinese culture. In short, they represent Adam and Eve who reconcile happily by accepting both Portuguese and Chinese cultures in the new Utopian Macau that is more hybrid and more tolerant in attitudes (Brookshaw, 2002).

The proposed idea was certainly embraced by Portugal and China alike. Nonetheless, idealistic as it may sound, Fernandes ends the novel with an epilogue narrated in the first-person mode, potentially the writer's own voice casting a strong sense of nostalgia and arousing a sense of awaiting trouble:

"I returned eight years later. The city of the Name of God remained structurally intact without the skyscrapers and motorcars of today. But one thing disappointed and saddened me. Chinese women of all social positions wore their hair either straight or curly, in accordance with Western hair styles. Nowhere did I catch sight of a bewitching braid, shaking rhythmically, like a serpent of temptation." (180)

According to the passage, it is made explicit that the change of Macau is regrettable to the speaker who describes Macau and its loss of Chinese identity. Although the image of the braids may have been seductive and fatalistic, he still prefers it to the Western hair styles, a symbol of hybidised, internationalised Macau in the post-independent world. The projected identity could very well mirror Macau and its colonial history but it may not be admired or upheld by all its citizens who may hope for the good old days in which Chinese identity prevailed. Therefore, despite the idealistic, optimistic proposition, the predicament over post-independent identity is still echoed in the final lines of Fernandes's work.

\subsection{Mammon Inc.}

Different from the previously discussed two novels, Mammon Inc. features post-independent, contemporary Singapore, of which national identity is at war between the Eastern spiritual values and the Western materialistic ones (Patke \& Holden, 2010). Chiah Deng Gan, a protagonist, is torn between a life of spiritual contemplation and the temptation of a material world, represented by the corporation of Mammon Inc. whose business corporations reign supreme all over the world.

An Oxford graduate, the female character is offered a position at one of the most influential establishments where her responsibility lies in assisting her international clients to adapt culturally. Her first two experiments are done on her British friend, Steve, and her sister in Singapore. In order to secure the tempting offer, Chiah Deng must help Steve fit in 
the Chinese cultural setting and her sister in the British one. While her sister's adaptation fails miserably, Steve's performance at a Chinese dining is impeccable. However, the success in turning Steve's identity upside down does not please her. Instead, she is compelled to ask herself a question of what her job really means and what it does to her. She recalls the feeling of loss as she "[i]s going round in circles like a decapitated chicken" (204). The symbolic decapitation could reflect Chiah Deng's downfall caused by her lack of identity. In the climatic moment, the character is trapped between the Eastern world she was born in and the Western world from where her education derives. Chiah Deng's dilemma is arguably comparable to that of Singapore. A small Asian island, Singapore was colonised by the British and after independence, it sought Western values and approval, illustrated in its trade, cultural universalism and infrastructure. The 'Asian Values' model was proposed as a standard of practice for people but instead of providing guidelines, it added a great deal of confusion over the construction of Singapore's national identity. Chiah Deng's constant indecision can therefore be read as the straddling position of Singapore in the modern world.

At the end of the novel, making a biblical allusion to the fruit of knowledge, the protagonist succumbs to the seductive Western power:

"I stared out at the glass castles that shimmered in the midday heat period. It was like looking down at a field of icicles. They say that Hades has warmth, and never had I seen a city like this, filled with icy blocks so cold and so hard that not even the summer sun could melt them.

"Don't you just love this view? he said.

I nodded, smiling bitterly. "Who can resist the big apple" I said.

The apple in Eve's eye." (278)

Her inability to resist the big apple suggests the current situation of Singapore with its advanced technology and Western guise. The cultural values of Europe, as the passage reads, have overcome the Chinese, Malay and Indian cultures that once formed the unique characteristics of the city state. In other words, contemporary Singapore has drastically changed and it has left the people, such as the main character in the novel, culturally adrift and unable to find their identity.

\section{Conclusion}

Anxiety over the notion of national identity is certainly palpable. The countries' ongoing journey to unfold their national identity can be interminable. Throughout the course of history, we have witnessed a number of countries, one after another, develop the awareness of national identity only to discover that it is very difficult, if not impossible, to identify the traits that they can really claim their own. European colonisation also intensified the difficulty of the search, especially in the former colonies whose cultures have been tainted by their intruders.

The three novels in this study very well illustrate the sense of unremitting struggle. All the three writers express their concerns with the future directions of their countries, especially in terms of national identity through their characters. While Never the Twain explicitly voices out the writer's concern, especially with regard to Hanafi's burial place, The Bewitching Braid offers an idealistic haven of cultural co-existence with the narrator's concerns and nostalgia simultaneously raised. Mammon Inc., distinct from the two novels in terms of temporal focus, shows the reader how fragile the notion of national identity is with the influences of the material world invented by the West. The use of 'decapitated chicken' implies the strong sense of identity loss.

Therefore, it is not too far-fetched to argue that the search for national identity is to be marching on and to be lasting as long as one can imagine. Writers of literature will be sure to follow and capture the travellers' sentiments and experiences in this exhaustive journey.

\section{Recommendations for Future Research}

This research has analysed three novels from East and Southeast Asia. The analysis focuses on the dilemmas faced by the people and the former colonies in attempting to define their national identities. As East and Southeast Asia are an abundant source of literary texts, those interested in the topic can deploy different novels from other countries such as Malaysia, Hong Kong and the Philippines in their future research and studies. In addition, they could also investigate other genres of literature such as poetry and drama in their analysis. Poetry in Singapore, for example, has flourished especially in the past 50 years. Such studies are sure to shed light on the issue discussed in this study. 


\section{References}

Anderson, B. (1983). Imagined communities. London, UK: Verso.

Boehmer, E. \& Chaudhuri, R. (2010). The Indian postcolonial: A critical reader. London, UK: Routledge.

Brookshaw, D. (2002). Perceptions of China in modern Portuguese literature: Border gates. Lewiston, New York: The Edwin Mellen Press.

Chabal, P. et al. (1996). The post-colonial literature of Lusophone literature. Evanston, Illinois: Northwestern University Press.

Dathorne, O.R. (1975). African literature in the twentieth century. London, UK: Heinemann.

Fanon, F. (1961). The wretched of the earth. London, UK. Penguin.

Fernandes, H.S. (1993). The bewitching braid (D. Brookshaw, Trans.). Hong Kong, Hong Kong: Hong Kong University Press.

Gopal, P. (2009). The Indian English novel: Nation, history, and narration. Oxford, UK: Oxford University Press.

Gover, D. et al. (Eds.). (1999). The Post-colonial condition of African literature. Trenton, New Jersey: Africa World Press.

Hall, G. (2005). Literature in language education. Hampshire, UK: Pelgrave Macmillan.

Helff, S. (2013). Unreliable truths: Transcultural homeworlds in Indian women's fiction of the diaspora. Portland, Oregon: Book News.

Hoadley, M.C. (1996). Ethnicity in modern Indonesian literature. In L. Littrup (Ed.), Identity in Asian literature (pp. 103-125). Surrey, UK: Curzon Press.

Huat. C.B. (1998). Racial Singaporeans: Absence after the hyphen. In J.S. Kahn (Ed.), Southeast Asian identities: Culture and the politics of representation in Indonesia, Malaysia, Singapore, and Thailand (pp. 28-50). Singapore, Singapore: Institute of Southeast Asian Studies.

Huntington, S.P. (2004). Who are we?: The challenges to America's national identity. New York, New York: Simon \& Schuster.

Kahn, J.S. (1998). Southeast Asian identities: Introduction. In J.S. Kahn (Ed.), Southeast Asian identities: Culture and the politics of representation in Indonesia, Malaysia, Singapore, and Thailand (pp. 1-27). Singapore, Singapore: Institute of Southeast Asian Studies.

Krishnan, M. (2014). Contemporary African literature in English: Global locations, postcolonial identifications. Hampshire, UK: Pelgrave Macmillan.

Kumar, K. (2003). The making of English national identity. Cambridge, UK: Cambridge University Press.

Moeis, A. (1928). Never the twain (R. Susanto, Trans.). Jakarta, Indonesia: Lontar.

Nguyen, N.H.C. (2003). Vietnamese voices: Gender and cultural identity in the Vietnamese Francophone novel. DeKalb, Illinois: Northern Illinois University Press.

Özkirimli, U. (2000). Theories of nationalism: A critical introduction. Hampshire, UK: Pelgrave Macmillan.

Patke, R.S. \& Holden, P. (2010). The Routledge concise history of Southeast Asian writing in English. London, UK: Routledge.

Pennycook, A. (1998). English and the discourse of colonialism. London, UK: Routledge.

Pina-Cabral, J. (2002). Between China and Europe: Person, culture and emotion in Macao. London, UK: London School of Economics Press.

Said, E. (1978). Orientalism. London, UK: Penguin.

Singh, K. (Ed.). (1998). Interlogue: Studies in Singapore literature. Singapore, Singapore: Ethos Books.

Smith, A.D. (1991). National identity. London, UK: Penguin.

Smith, A.D. (1992). National identity and the idea of European unity. International Affairs, 68(1), 55-76.

Spillman, R. (Ed.). (2009). Gods and soldiers: The penguin anthology of contemporary African writing. London, UK: Penguin.

Spivak, G.C. (1988). In other worlds: Essays in cultural politics. London, UK: Routledge.

Tan, H.H. (2001). Mammon inc.. London, UK: Penguin.

Thumboo, E. (Ed.). (2007). Writing Asia: The literature in Englishes. Singapore, Singapore: Ethos Books.

Varughese, E.D. (2013). Reading new India: Post-millennial Indian fiction in English. London, UK: Bloomsbury.

Wei, C.X.G. (Ed.). (2014). Macao: The formation of a global city. London, UK: Routledge.

Wong, K.K. \& Wei, C.X.G. (Eds.). (2014). Macau: Cultural interaction and literary representation. London, UK: Routledge.

Xi, X. \& Ingham, M. (Eds.). (2003). City voices: Hong Kong writing in English 1945 to the present. Hong Kong, Hong Kong, Hong Kong University Press. 